Madrygal. Revista de Estudios Gallegos

ISSN: 1138-9664

\title{
A clasificación das variedades dialectais do galego de Ricardo Carvalho Calero ${ }^{1}$
}

\author{
Francisco Dubert-García ${ }^{2}$
}

Recibido: 1 de setembro de 2021 / Aceptado: 15 de outubro de 2021

\begin{abstract}
Resumo. Neste traballo pretendo analizar a obra dialectolóxica de Ricardo Carvalho Calero; en concreto, voume centrar na súa proposta de clasificación das variedades dialectais do galego. Para iso, presentarei, en primeiro lugar, a súa visión do galego como lingua unitaria: aínda que presenta variación dialectal, non contén dialectos no seu interior, senón entidades que el denomina modalidades. En segundo lugar, prestarei especial atención a como elaborou a súa clasificación, ós seus presupostos teóricos e describirei a proposta en si mesma. Tamén analizarei algunhas das críticas que outros autores realizaron sobre aquela. A análise sobre este último aspecto non ten un mero valor historiográfico local, senón que oculta importantes cuestións teóricas previas á realización das investigacións dialectais. Finalmente, conclúo que, a pesar da pouca información con que don Ricardo contaba, a súa organización das falas galegas estaba ben fundamentada e segue a merecer o noso respecto.
\end{abstract}

Palabras chave: Ricardo Carvalho Calero; dialectoloxía galega; historia da lingüística galega; galego; portugués.

\section{[es] La clasificación de las variedades dialectales del gallego de Ricardo Carvalho Calero}

Resumen. En este trabajo pretendo analizar la obra dialectológica de Ricardo Carvalho Calero; en concreto, me voy a centrar en su propuesta de clasificación de las variedades dialectales del gallego. Para eso, presentaré, en primer lugar, su visión del gallego como una lengua unitaria: aunque presenta variación dialectal, no contiene dialectos en su interior, sino entidades que él denomina modalidades. En segundo lugar, prestaré especial atención a cómo elaboró su clasificación, a sus presupuestos teóricos y describiré la propuesta en sí misma. También analizaré algunas de las críticas que otros autores han realizado sobre aquella. El análisis sobre este último aspecto no tiene un mero valor historiográfico local, sino que oculta importantes cuestiones teóricas previas a la realización de las investigaciones dialectales. Finalmente, concluyo que, a pesar de la poca información con que don Ricardo contaba, su organización de las hablas gallegas estaba bien fundamentada y sigue mereciendo nuestro respecto.

Palabras clave: Ricardo Carvalho Calero; dialectología gallega; historia de la lingüística gallega; gallego; portugués.

\section{[en] Ricardo Carvalho Calero's Classification of Galician Dialectal Varieties}

\begin{abstract}
This paper aims to analyze Ricardo Carvalho Calero's dialectological work; more specifically, we will focus on this author's proposed classification of Galician dialectal varieties. We will begin by presenting his vision of Galician as a unitary language; that is, even though dialectal variation is present, the language does not include dialects, but rather entities that the author called modalities. We will then take a closer look at the development of Carvalho Calero's classification and its theoretical foundations, as well as provide a description of this proposal. Some of the criticism this proposal has received is also analyzed. The analysis of this latter aspect does not merely have local historiographical value but also reveals important theoretical considerations preliminary to dialectal research. Finally, we conclude that, despite the scarce information that Ricardo Carvalho Calero had available, his organization of the Galician geographical varieties was well-founded and is still deserving of our respect.
\end{abstract}

Keywords: Ricardo Carvalho Calero; Galician Dialectology; History of Galician Linguistics; Galician; Portuguese.

1 Traballo realizado no proxecto Variación y cambio en los dominios gallego y portugués en el siglo XX: análisis del habla rural a partir de materiales geolingüísticos (Ministerio de Ciencia, Investigación y Universidades, PGC2018-095077-B-C44); contou tamén coa axuda da Xunta de Galicia (Fondos FEDER, ED431C 2021/20). Quero mostrar o meu agradecemento a Xulio Sousa polos seus comentarios.

2 Universidade de Santiago de Compostela. Instituto da Lingua Galega.

Correo-e: francisco.dubert@usc.es; ORCID: https://orcid.org/0000-0001-7904-322X. 
Sumario. 1. Introdución. 2. A unidade do galego popular. 3. A clasificación dos dialectos do galego realizada por don Ricardo. 3.1. A clasificación no seu contexto científico. 3.2. A proposta de Carvalho Calero. 4. Conclusións. 5. Referencias bibliográficas.

Como citar: Dubert-García, F. (2021): “A clasificación das variedades dialectais do galego de Ricardo Carvalho Calero", en Madrygal. Revista de Estudios Gallegos 24, pp. 69-80, DOI: http://dx.doi.org/10.5209/madr.80234.

\section{Introdución}

Ricardo Carvalho Calero (1910-1990) foi o primeiro catedrático de Lingua e Literatura Galegas da Universidade de Santiago de Compostela (1972), onde comezara a dar clases en 1965 (Carballo Calero 1968); cómpre recordar que en Galicia non houbo estudos universitarios regrados destas materias ata ese momento, o que axuda a explicar o enorme atraso que acumulou a lingüística galega ata a década dos anos setenta do século XX. Entre outras obras relevantes para a nosa cultura, Ricardo Carvalho Calero foi autor dunha Gramática elemental del gallego común, en que pretendía presentar un modelo de lingua normativo. Publicada en 1966 pola Editorial Galaxia (e con sucesivas reedicións e reelaboracións), esta gramática transformouse na obra de referencia sobre a lingua galega durante máis de vinte anos. Don Ricardo publicou tamén unha proposta de clasificación dos dialectos galegos que incluía, ademais, unha contextualización lingüística e histórica do galego con relación ó castelán e ó portugués. Aínda que co paso do tempo o noso estudoso mudou o seu pensamento sobre a posición do galego a respecto do portugués, mantivo inalterada a súa proposta de clasificación interna dos dialectos galegos. Co tempo, esta clasificación foi quedando esquecida na lingüística galega, pois acabou por se impor a hoxe canónica de Fernández Rei (1990). Esta última interpretación da nosa realidade dialectal prevaleceu por varias razóns: en primeiro lugar, após a realización das enquisas do Atlas Lingüístico Galego, Fernández Rei manexaba unha gran cantidade de información xeolectal que era moi fiable (xa que se obtivo dun modo sistemático por meo de enquisas realizadas in situ); ademais, Fernández Rei realizou atractivas representacións visuais da súa proposta; finalmente, a súa visión era conceptualmente máis sinxela e clara cá de don Ricardo.

Mentres que xa existen varios traballos que analizan a obra de don Ricardo como gramático (Santamarina 1982a; Regueira 1996;
Henríquez Salido 1999; Alonso Pintos 2000; Dubert-García 2000, 2020b; Mariño Paz 2002; Álvarez 2003, 2011; Sánchez Rei 2005, 2008; Freixeiro Mato 2018, González González 2020), escasean os centrados no seu labor dialectolóxico. Por esta razón, neste traballo pretendo analizar a obra de don Ricardo como dialectólogo; en concreto, voume centrar na súa proposta de clasificación das modalidades do galego (Carballo Calero 1969, 1978, 1979); para iso, prestarei atención ó modo en que a elaborou, ós seus presupostos teóricos e ás críticas que outros autores realizaron sobre ela; nótese que as reflexións que vou presentar non teñen un mero valor historiográfico local, pois ilustran importantes debates teóricos previos á realización dunha investigación dialectolóxica.

Antes de máis, debo indicar que na maior parte da obra de Ricardo Carvalho Calero que vou citar o seu apelido aparece coa variante ortográfica Carballo, pois só tardiamente asinou como Carvalho. Por esta razón, referireime a el chamándolle don Ricardo para así evitar os molestos saltos entre Carvalho/Carballo (nas referencias bibliográficas, claro está, empregarei a ortografía recollida en cada título).

\section{A unidade do galego popular}

Son moitos os lingüistas galegos que destacan a unidade da lingua galega (por exemplo, García de Diego 1909: 155; Alonso Montero 1969: 80; Fernández Rei 1990: 34-38; Sánchez Rei 2011: 168-169): recoñécese a existencia de variación xeolingüística (non pode ser doutro xeito), pero sempre se considera que esta non é suficiente para provocar a fragmentación do galego en distintos dialectos. Don Ricardo foi pioneiro en manter esta unidade interna do galego:

Comencemos por reitificar a opinión vulgar segundo a cal o galego está pulverizado en dialectos. A cohesión lingüística do galego é, polo contrario, sorpendente. O noso idioma deixóu de ser prácticamente lingua escrita durante toda a Edade Moderna. As comunicacións en Galicia foron sempre dificis. Nestas condicións podería se prever unha fragmentación dialectal moi minuciosa. (Carballo Calero 1969: 6)

Para el, "as diferencias ou preferencias de vocabulario, de xiros sintácticos ou de miudas variantes na realización de algúns fonemas, non supoñen pluralidade dialectal", pois esta baséase na "conciencia dialectal"; en definitiva, "o galego se nos presenta como unha lingua 
dotada dunha poderosa unidade estructural" (Ibid.: 6, sic). Estas ideas repítense en traballos posteriores (coma Carballo Calero 1978, 1979):

Lo que llama la atención en el gallego es su uniformidad más bien que su fragmentación. Lo quebrado del terreno, la ausencia de buenas comunicaciones, el estado secular de la lengua en condiciones de abandono literario han estado lejos de producir una pulverización del idioma en dialectos. La uniformidad relativa es tan notoria que se ha negado la existencia de grupos dialectales. (Carballo Calero 1979: 78)

Nótese que por dialectos don Ricardo, Fernández Rei ou Sánchez Rei entenden variedades lingüísticas tan características que os falantes poden identificalas, individualizalas e nomealas ${ }^{3}$. Máis adiante, don Ricardo engadirá outra razón para negar a existencia de dialectos en galego: a inexistencia de "sustantividades diverxentes que entrañen a imposibilidade de intercomunicación" (Carballo Calero 1978: 348). En definitiva, dadas a falta de consciencia dialectal e a intelixibilidade mutua, don Ricardo prefire indicar que no seo do galego popular encontramos diversas modalidades, pero non dialectos ${ }^{4}$.

\section{A clasificación dos dialectos do galego realizada por don Ricardo}

É momento xa de presentar a clasificación das falas galegas realizada por don Ricardo. Para iso, primeiro situareina no seu contexto científico, pois esta revisión iluminará a nosa visión da súa clasificación; despois, analizarei a proposta en si. Como se verá, non están aquí ausentes problemas teóricos básicos do traballo dialectolóxico.

\subsection{A clasificación no seu contexto científico}

O primeiro ensaio de clasificación de valor lingüístico dos dialectos galegos ${ }^{5}$, elaborado sobre unha base de datos dialectais empírica e sistemática, é o realizado por Zamora Vicente (1986 [1953]: 34), quen establece que "creo que ya se puede ir viendo con cierta precisión que hay dos claros subdialectos: uno oriental o continental ( $\mathbf{x}$ y $\mathbf{g}$ diferenciadas, distinción entre $\mathbf{s}$ y $\boldsymbol{\theta}$, terminación $-a o$ ) y otro occidental o atlántico (geada, seseo, -an)". A Figura 1 mostra un cartografado das áreas, que nos indica a existencia de áreas de transición entre os dous subdialectos.

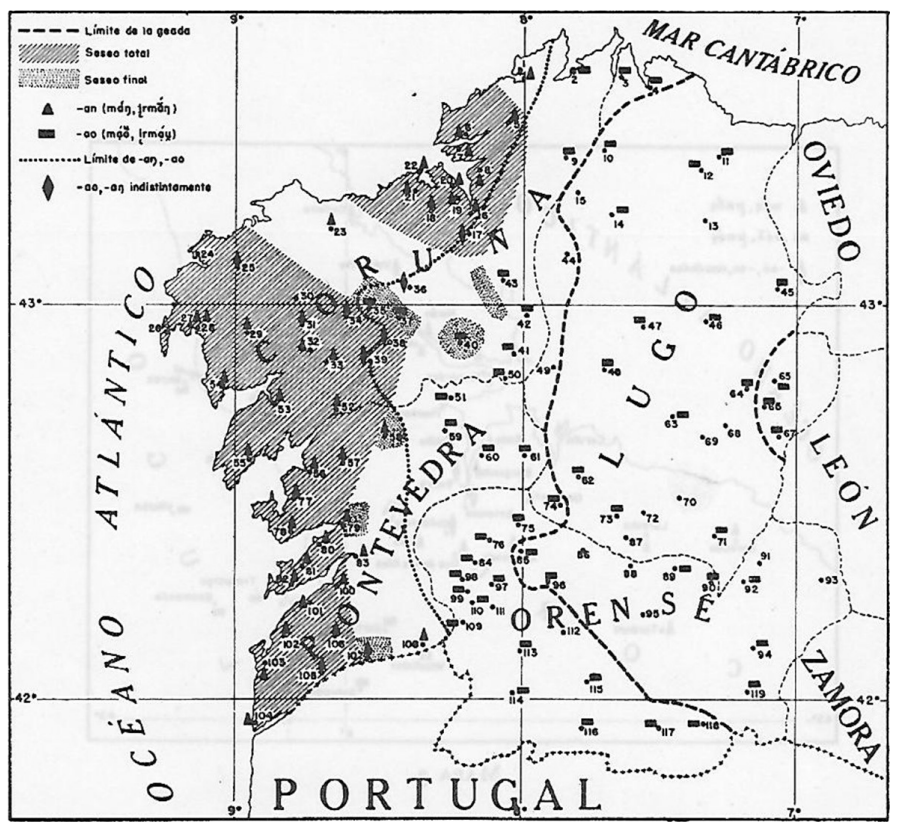

Figura 1. Os subdialectos do galego segundo Zamora Vicente (1986 [1953]: 29)

3 Con todo, a afirmación da inexistencia de dialectos (usando a palabra dialecto no sentido sinalado arriba) é válida para o galego falado en Galicia: segundo o mapa 4 do ALPI 1962, os asturianos de fala galega chámanlle á súa variedade chapurriado (e variantes) ou, mesmo, ibiano.

4 Dubert-García 2020a: 149 atribúe esta insistencia na unidade a un elemento ideolóxico, pois a diversidade dialectal ten sido usada para negarlle a existencia ás linguas minorizadas de estandarización recente, coma o galego, o asturiano ou o vasco.

5 Sánchez Rei 2011 ofrece unha completa síntese histórica da dialectoloxía galega. 
Na súa revisión desta proposta, don Ricardo sinala que dado que as isoglosas detectadas por Zamora Vicente non coinciden, "non podemos trazar unha fronteira xeográfica precisa antre os dous dialectos. Non sabemos ónde remata para Zamora Vicente o galego occidental e ónde comenza o oriental"; máis aínda: pregúntase don Ricardo que facer con puntos coma Arbo, "onde hai -an e gheada, pero non seseo", ou coma Lalín, "onde hai gheada, pero non -an nen seseo" (Carballo Calero 1969: 9).

O certo é don Ricardo estase a enfrontar ós problemas que ocasiona un contínuum xeolectal (termo que non aparece nos traballos citados) ó pretender introducir nel fronteiras entre variedades cando o contínuum só contén fronteiras entre fenómenos illados. Este problema será un dos motores da súa clasificación. Moi agudamente conclúe que

Estas dificultades danse sempre que se queren delimitar zonas xeográficas segundo un conxunto de fenómenos lingüísticos. Hai que admitir zonas de transición e mestura de rasgos distintivos. No mundo dos feitos, hai un galego de -an e outro que esclúi esta forma, un galego de seseo outro en que non hai seseo, etc. Estes rasgos clasifícanse en occidentás e orientás, e onde concurren, o ponto será descrito como pertencente ao dialecto ocidental por tales rasgos, e ao oriental por tales outros. (Ibid.: 9)

A consciencia da dificultade de trazar límites entre dialectos por mor do contínuum xeolectal agudízase máis adiante:

Si podemos, previo el estudio correspondiente, determinar con exactitud cómo se habla en un determinado lugar, la pretensión de trazar fronteras dialectales para dividir el país en provincias lingüísticas, ofrece dificultades serias, pues cada rasgo idiomático tiene su propia difusión, que no tiene por qué coincidir con la presencia de otros determinados en determinado espacio. (Carballo Calero 1979: 78)

A pesar da evidencia de que cada trazo dialectal ten a súa propia extensión xeográfica, Zamora Vicente emprega "un conxunto de rasgos" para definir os seus dialectos; deste modo, se aplicamos o seu método, só encontramos dialectos "puros" nas falas en que conflúen tódolos trazos indicados; por forza, os outros dialectos que non comparten a totalidade dos trazos deben ser transicións. Da súa análise crítica da proposta de Zamora Vicente, don Ricardo acaba por concluír que
Mellor será, pois, non vencellar sistemáticamente os distintos tipos fundamentáis de galego a zonas xeográficas estrictas; aínda que a concurrencia de rasgos que definen cada modalidade soe abranxer un ámbito territorial dabondo deseñado, mais non ata o extremo de que os límites sexan nidios e non se podan rexistrar, como é natural, anomalías, contaminacións e diverxencias locáis. (Carballo Calero 1978: 350-351)

Polo tanto, como veremos a seguir, a preocupación de don Ricardo non vai ser orientar a súa clasificación dialectal con referencias xeográficas (galego oriental, galego central, galego atlántico), senón crear conxuntos de falas, que denomina modalidades, definidas por conxuntos de trazos compartidos, e non dialectos. Escolle o termo modalidade porque lle parece "de connotacións máis neutras", que nos sitúa "nun terreo onde cabe unha amplísima medida de acordo, pois modalidades son tanto as variantes que poden independizar dúas fórmulas lingüísticas como aquelas que representan nada máis que inflexións normalizadas na realización do sistema" (Ibid.: 349). As modalidades son, pois, entidades creadas polo labor descritivo e organizador do lingüista e non entidades histórico-sociais que emerxen entre os falantes debido á "consciencia dialectal". Dubert-García (2020a) chámalles entidades etic ás creadas polos lingüistas e entidades emic ás creadas polos falantes.

Polo tanto, non vai falar de galego oriental, nin occidental, senón das modalidades A, B, $\mathrm{C}$ e D. Deste xeito, os trazos empregados para crealas permítenlle "unha clasificación das distintas falas galegas en catro modelos, que chamamos A, B, C e D" (Carballo Calero 1978: 351). Cómpre indicar que don Ricardo non xustifica por que selecciona estas variables e non outras, ou por que delimita catro modalidades: todo o máis que encontramos é que algunhas variables parecen favorecer máis ca outras "importantes diferencias de conciencia lingüística” (Ibid.: 350; véxase tamén 1969: 9); de feito, parecen variables dialectais que se poden transformar en estereotipos, no sentido de Labov (1983 [1972]: 387-388). En todo caso, as variables seleccionadas acabaron xogando papeis importantes, por exemplo, nos traballos de Fernández Rei: por exemplo, as variante camín caracteriza o bloque oriental (Fernández Rei 1990: 140); a gheada e o seseo posnuclear, a variantes irmán, cans, o bloque occidental (Ibid.: 116) etc.

Neste sentido, cómpre destacar que, como me suxire Xulio Sousa nun comentario persoal, 
resulta estraño que o autor non nos diga de onde toma os datos (cousa que si fai, por exemplo Zamora Vicente nos seus traballos); tamén resulta estraño que don Ricardo non cite xamais a edición dos setenta mapas do ALPI publicados en 1962 (ALPI 1962) que, como mostra Dubert-García (2021), lle serían de grande utilidade para trazar algunhas isoglosas.

Por outra parte, a localización xeográfica das falas parece menos importante cá creación dos modelos, "os dous primeiros inscritos dentro do galego iriense -suroccidental e noroccidental-, e os outros dous dentro do galego lucense -central e oriental" (1978: 351). Todas estas modalidades están rodeadas de falas de transición que se orientan ás diferentes modalidades en diferentes graos:

Las circunstancias históricas han hecho que se entremezclen muchos de estos rasgos locales, de modo que, aparte de los enclaves existentes, se forman haces muy complejos de isoglosas. No es posible, pues trazar límites geográficos precisos para las formas dialectales que postulamos como unidades lingüísticas, aunque podamos hacerlo para cada una de las variantes fonéticas o morfológicas que caracterizan las distintas hablas. De todas maneras, reteniendo la existencia de zonas de transición, y admitiendo que una división dialectal geográfica es siempre, o casi siempre, una abstracción metódica de la realidad compleja, los esquemáticos cuadros trazados nos permiten hablar de cuatro tipos principales, el suroccidental, el noroccidental, el central y el oriental, por lo que se refire al gallego hablado. (Carballo Calero 1979: 82-83)

Na miña opinión, o método de don Ricardo é unha depuración do empregado por Zamora Vicente; o lingüista ferrolán puido, ademais, ver confirmado o seu método trala lectura de Porzig (1969 [1950]), un libro traducido ó castelán polo seu compañeiro de facultade, Abelardo Moralejo. Don Ricardo cita as notas sobre o galego con que o latinista compostelán enriquece a exposición sobre dialectoloxía de Porzig; estas citas de Moralejo indican a lectura do propio traballo de Porzig.

Efectivamente, Porzig di que os auténticos dialectos locais alemáns (fronte ás variacións dialectais do alemán estándar) son "modalidades bien localizadas del alemán, que se reconocen y distinguen al primer golpe de vista" (Ibid.: 239). Nótese o uso da palabra modalidades. A seguir continúa con que "cada uno de estos dialectos es tanto inclusivo como exclusivo en relación a los otros, lo mismo que lo es el alemán como un todo frente a las lenguas extranjeras". Porzig propón unha viaxe de Turinxia á Alta Baviera no medio da que encontrariamos tres dialectos: o turinxio, o francón e o bávaro. Ora ben, estes dialectos teñen límites difusos e os falantes das aldeas próximas poden comunicarse entre eles sen grandes problemas, algo que non sucede cos habitantes de aldeas máis distantes; isto débese, obviamente, a que:

Pequeñas diferencias que han ido escapando a nuestra atención sobre el terreno aisaladamente, se han acumulado, desde luego, a gran distancia, como para haber dado al fin por resultado modos de hablar muy diferentes. Parece como si se extendiera sobre el país una red simétrica de pequeñas divergencias lingüísticas, que de cuando en cuando a determinada distancia alcanzasen una magnitud claramente visible. Pero entonces podría preguntarse si no es arbitrario destacar ciertos lugares como modelos dialectales y designar los dialectos entre ellos como "transiciones". (Ibid.: 239-240)

Porzig pregúntase como identificar os modelos e as transicións, pois ben podería ser que unha zona declarada transición fose mellor declarable modelo (ou viceversa); se así fose, calquera clasificación dialectal sería convencional, froito simplemente dun acordo, "y podría ser igualmente sustituida por otro cuadro totalmente distinto, según los puntos firmes que uno elija" (Ibid.: 240). Como solucionar este problema e conseguir establecer os dialectos e as súas zonas centrais dun modo máis obxectivo?

Segundo Porzig, "se hace una lista de todas o, por lo menos, de las más importantes divergencias que se dan, en suma, entre dos dialectos, y se comprueba sobre el terreno, de aldea en aldea, cómo se comportan los modos de hablar frente a estas divergencias". Unha vez que se representa nun mapa a distribución das variantes de cada variable analizada, sabendo que cada isoglosa ten o seu propio trazado, aparecerán áreas centrales, "dentro de las cuales es en general uniforme el modo de hablar", pois comparten tódolos trazos designados, $\mathrm{y}$ áreas marginales o de transición, en las cuales varía rápidamente de lugar en lugar" (Ibid.: 244) e non aparecen os conxuntos completos de trazos. En definitiva, o método de Porzig (Ibid.: 245) mostra que "hay realmente una comunidad más estrecha del dialecto y que estas comunidades más estrechas están enlazadas entre sí por medio de transiciones. Así, pues, nos hace ver objetivamente la comunidad de 
comunidades en el aspecto local". Estas comunidades estreitas son as modalidades que don Ricardo pretende identificar.

No mesmo sentido se manifesta Coseriu (1981: 26) cando sostén que "los límites «dialectales» no son de antemano límites entre «dialectos»", pois non existen fronteiras "entre modos de hablar uniformes". Segundo Coseriu, este feito xustifica que haxa dialectoloxía. Desde o punto de vista dos dialectos,

la no coincidencia entre varios límites dialectales significa sólo que tienen muchas «fronteras» posibles, o sea, que entre los sistemas dialectales hay interferencias y que entre los dialectos mejor caracterizados suele haber dialectos intermedios o «de transición». Y los dialectos pueden compararse con respecto a lo que tienen en común y a lo que tienen de diferente en sus «centros», aunque entre sus límites haya interferencia. (Id.)

Para Coseriu, a finalidade primeira da dialectoloxía non é establecer límites entre dialectos (ou áreas, ou bloques), senón comprobar a configuración diatópica da lingua histórica: "los límites efectivos de la uniformidad idiomática". As fronteiras "podrán resultar de la coincidencia entre muchas isoglosas particulares o fijarse convencionalmente (por ejemplo, haciéndolas coincidir con ciertas isoglosas consideradas como particularmente significativas)" (Ibid.: 27, cursivas engadidas). Outra vez, unidades centrais, modalidades, e áreas de transición.

Xa antes Coseriu (1985 [1956]: 137) indicaba que os dialectos non son cousas, senón abstraccións, "sistemas de isoglosas que se establecen por encima de la multiformidad del hablar". En canto ás isoglosas que se tomen como límite, indica que se toman por convención; porén esta convención non é totalmente arbitraria, "porque no todas las isoglosas tienen la misma importancia"; polo tanto, observar que certas isoglosas non coinciden significa só "que hay interferencias entre los «dialectos», en el sentido definido" (Ibid.: 138).

En definitiva, en 1969, don Ricardo non fai outra cousa ca aplicar un dos métodos científicos do seu momento: con tan só nove trazos que considera significativos ou importantes (quizais por razóns perceptivas) realiza catro agrupamentos de falas que buscan comprobar a configuración diatópica do galego. En todo caso, cómpre insistir en que existen diferenzas fundamentais entre a situación lingüística alemá descrita por Porzig e a galega referida por don Ricardo. En primeiro lugar, en Alemaña existen dialectos emic, con nome propio, coma o turinxio ou o francón, identificados polos falantes; en Galicia non existen tales dialectos: as modalidades son entidades etic creadas polo lingüista que non se ligan a unidades emic creadas polos falantes por medio da súa consciencia dialectal ${ }^{6}$. En segundo lugar, no contínuum xermánico hai problemas de intelixibilidade mutua entre os falantes dos diversos dialectos; no contínuum galego estes problemas non existen, de modo que un falante da Fonsagrada comprende un falante de Carnota.

Polo tanto, a proposta de Carvalho (Carballo Calero 1969, 1978, 1979) segue os métodos de Zamora Vicente (1986 [1953]), de Porzig (1969 [1950]) e de Coseriu (1981, 1985 [1956]): selecciona varios trazos para identificar as súas modalidades.

Resulta interesante contrastar a proposta de don Ricardo coa de Cintra (1971) ou coa hoxe canónica de Fernández Rei (1990, 1994). Estas últimas diferéncianse da visión de don Ricardo porque os seus autores se decantan por primar un só trazo á hora de establecer os límites entre os grupos de dialectos (Cintra 1971) ou entre os bloques (Fernández Rei 1990, 1994).

Canto á proposta de Cintra, en primeiro lugar, cómpre indicar que o dialectólogo portugués realiza dous anos despois a súa clasificación dos dialectos galegos sen tan sequera citar o traballo de don Ricardo (Carballo Calero 1969) e ignorando os datos e reflexións que alí se conteñen, tanto das relacións entre galego e portugués, coma da división interna dos dialectos galegos. Vale a pena mostrar que Cintra (1971) detecta un contínuum xeolectal dentro do territorio politicamente portugués ${ }^{7}$, mais percibe unha fronteira nidia entre os dialectos galegos e os portugueses setentrionais. Para el, esta fronteira "não parece oferecer dificuldades

6 Outra vez vale a pena recordar que esta descrición vale para o galego de Galicia. No galego de Asturias, os falantes non adoitan chamarlle galego á súa lingua, véxase Llera Ramo e San Martín Antuña 2003: 87-88.

7 Segundo Cintra 1971: 104: "As isófonas correspondentes aos vários traços que separam o grupo português setentrional do grupo português centro-meridional estão longe de coincidir e de se sobrepor. Pelo contrário, cruzam-se seguindo traçados bastante diversos, embora sempre dentro de uma região que, a não ser em alguns casos, nos extremos oriental e ocidental, é limitada pelos rios Douro, ao Norte, e Tejo, ao Sul". 
de maior, dada a coincidência quase perfeita das isófonas correspondentes aos vários fenómenos reunidos": os trazos dialectais que separan galego e portugués setentrional son "claramente diferenciadores e individualizadores desses grupos de dialectos" (Ibid.: 104). Con todo, a pesar da fronteira clara que percibe entre os dialectos galegos e portugueses, Cintra considera sempre o galego como un dialecto do portugués ${ }^{8}$.

En consecuencia, Cintra decide seguir un método distinto ó de don Ricardo e de Zamora Vicente á hora de organizar a realidade dialectal do portugués: unha estrutura xerárquica bimembre baseada na selección dun único trazo como límite entre dialectos, subdialectos e falas. Neste punto Cintra afirma seguir a doutrina de Badía Margarit (1951: 70): “el punto crítico de la división de un dominio en dialectos es el establecimiento del criterio según el cual se realiza esta división; lo mejor es adoptar un solo rasgo distintivo muy significativo"9. Deste xeito, Cintra separa galego-portugués de ástur-leonés e castelán pola famosa isoglosa de ditongación de ě e ŏ latinos; xebra os dialectos galegos dos dialectos setentrionais portugueses pola presenza/ausencia de sibilantes coronais voceadas; e, para o galego, fundamentándose "nos importantes estudos recentemente publicados sobre dialectologia galega por Alonso Zamora Vicente" (Cintra 1971: 82), considera o galego divido nun galego occidental con gheada e un galego oriental sen gheada (sempre sendo consciente das illas de gheadas orientais).

En resumo, a diferenza de don Ricardo e de Zamora Vicente, Cintra delimita por medio dunha soa isoglosa, a da gheada, un "grupo de dialectos galegos ocidentais de um grupo de dialectos galegos orientais, ou seja, uma zona galega ocidental de uma zona galega oriental" (Ibid.: 108).
Pola súa parte, Fernández Rei (1990) divide o territorio de fala galega non en dialectos, senón en bloques e áreas dialectais; as súas razóns para evitar o termo dialecto son de carácter sociolóxico, exactamente equivalentes ás de don Ricardo:

A pesar da variedade, convén salienta-lo feito de que a unidade do galego vivo é moi grande; non pode falarse de fragmentación dialectal ó non sentiren os falantes como profundas e definitorias as diferencias lingüísticas, o que non quere dicir que o estudioso da lingua galega non poida delimitala en áreas lingüísticas, baseándose na combinación de fenómenos nalgunhas zonas concretas, fenómenos que as caracterizan e definen fronte ás veciñas. (Ibid.: 36)

En todo caso, para establecer os seus bloques, Fernández Rei segue aparentemente o método de primar unha soa isoglosa, no seu caso, o plural dos substantivos e adxectivos de acentuación oxítona rematados en consoante nasal: ladróns, ladrós, ladrois ${ }^{10}$. Realmente, non emprega unha isoglosa, senón dúas: a isoglosa ladróns/ladrós, que separa galego occidental de galego central; e a isoglosa ladrós/ladrois, que separa galego central de galego oriental. Estas dúas isoglosas crean un primeiro nivel de análise, os bloques: occidental (ladróns), central (ladrós) e oriental (ladrois). Á súa vez, estes bloques subdivídense internamente en áreas, as áreas en subáreas e as subáreas en microsubáreas; con todo, todas estas unidades inferiores ós bloques delimítanse por conxuntos de isoglosas e non por isoglosas individuais (o que volve a dar lugar a transicións entre elas, véxase un exemplo en Dubert García 1995: 96-98).

Segundo Fernández Rei (1994: 98), as modalidades de don Ricardo "resultan superficiais de máis"; tamén di que constitúen "unha división simple e esquemática", pois o autor

8 Por exemplo, ó comentar a proposta dialectal de Paiva Boléo e Santos Silva, Cintra 1971: 91 dinos que estes autores exclúen dos mapas "os dialectos ou falares portugueses que se falam para além das fronteiras políticas do Portugal eurpeu"; do mesmo xeito, non se explica nada no texto "das variedades regionais do português faladas em território polìticamente espanhol - muito principalmente ao galego, idioma nativo de uma região muito vasta, mas também aos falares de Alamedilha, Eljas, S. Martín de Trevejo e Valverde del Fresno e ao falar de Olivença".

9 Segundo Badía Margarit 1951: 70, a selección da desinencia da $1^{a}$ persoa do singular do presente de indicativo na primeira conxugación para realizar a división dialectal do catalán "permite unificar el hecho diferencial, corrobora la mencionada división entre catalán oriental y occidental, y da más valor científico a la división dialectal que antes había ensayado P. Barnils y que resulta ratificada con la aplicación del nuevo método".

10 Fernández Rei 1982: 282 e 1985b: 92 xebra os bloques occidental e central con dúas isoglosas, cans/cas e irmán/ irmao; no entanto, Fernández Rei 1990: 110 e 1994: 102 emprega só a isoglosa cans/cas. Por outra parte, Fernández Rei 1985a, un traballo escrito en 1980, recoñecía a existencia só de áreas, non bloques. 
"manexou un material fragmentado e inconexo" (Ibid.: 99). Porén, acabamos de ver que don Ricardo, creando esquemas, aplicou un dos métodos científicos do seu tempo: seleccionou un conxunto de variables para establecer modalidades, modelos dialectais, variedades centrais que tivesen tódolos trazos e, como veremos, tentou situar as restantes falas como transicións con respecto a estas variedades modélicas. Don Ricardo non esqueceu que as súas modalidades dialectais eran abstraccións, esquemas, prototipos (que se debían establecer seleccionando só parte da información) e non obxectos; para don Ricardo, como para Coseriu, a finalidade primeira da dialectoloxía non é establecer límites entre dialectos (ou áreas, ou bloques), senón comprobar a configuración diatópica da lingua histórica ${ }^{11}$.

\subsection{A proposta de Carvalho Calero}

Como acabamos de ver, conforme unha parte da dialectoloxía europea do seu tempo, don Ricardo preocúpase sobre todo de establecer modalidades prototípicas que se definen por compartir unha serie de trazos, rodeadas doutras variedades transicionais que se inclinan máis ou menos a unhas variedades prototípicas ou a outras.

En primeiro lugar, considera que o galego occidental de Zamora Vicente é realmente un galego suroccidental e o oriental de Zamora Vicente é un galego central; a carón destes dúas modalidades, establece un galego noroccidental, que, para el, é un galego suroccidental evolucionado ("ao menos a súa morfoloxía podería se espricar como un desgaste déste" (1969: 10); e crea un novo galego oriental, que considera un galego central arcaico. Deste xeito, o galego noroccidental é unha innovación do suroccidental; e o central unha innovación do oriental. Á súa vez, considera o galego noroccidental unha transición ó galego central; e o seu novo galego oriental unha transición ó leonés.
Esta visión lingüística depúrase moito máis na edición na súa Gramática (Carballo Calero 1979: 80-82) cunha maior riqueza de datos, pero, outra vez, establecendo as catro modalidades entre as que volve a sinalar "dependencias". Neste caso, chega a dicir que se pode falar da existencia de dous galegos: "el occidental (o atlántico) y el oriental (o continental), cada uno con una dependencia, el noroccidental y el extremo-oriental, respectivamente, de los cuales el primero representa una forma evolutiva, y el segundo una forma arcaica" (Ibid.: 83, n. 13) ${ }^{12}$. En todo caso, nestas consideracións sobre as modalidades non existe ningunha referencia á súa posible conexión coas variedades portuguesas do norte: o galego é tratado dun xeito autónomo.

A estes factores lingüisticos que pretenden organizar o espazo xeolectal, Carballo Calero (1969) súmalles consideracións de tipo sociolóxico: "A consciencia social corrobora a división tetrapartita [galego suroccidental, noroccidental, central e oriental]: como o ferrolán [noroccidental] se sinte distinto do 'meiriño' [suroccidental], o lugués [central] síntese distinto do 'buronés' [oriental]' (Ibid.: 11, encorchetados meus). Estas consideracións sociolóxicas desaparecen dos traballos posteriores $(1978,1979)$.

Don Ricardo ten sido criticado por atender a estes factores sociolóxicos e ás crenzas dos falantes, tanto na selección dos trazos coma na determinación das modalidades (Santamarina 1982b: 167-168). Porén, parece ser universal o consenso na lingüística galega de que en galego non hai dialectos porque os falantes non senten que haxa tales divisións; e a mesma consideración de galego e portugués como linguas distintas tamén descansa en factores sociolóxicos e non lingüísticos (véxase, por exemplo, Fernández Rei 1990: 17-18).

En virtude de todos estes elementos, don Ricardo selecciona 9 trazos dialectais de cuxa combinación saen as catro modalidades definidas en $\S 3$ e que se mostran na Táboa 1 .

11 "Si los límites dialectales fueran «fronteras» entre dialectos uniformes (es decir, si hubiese en todo caso coincidencia total entre esos límites), no habría, propiamente, variedad espacial de las lenguas, sino solo disposición espacial de los dialectos, y la dialectologia no tendría objeto autónomo, pues coincidiría con la gramática contrastiva «sintópica» de éstos" (Coseriu 1981: 27).

12 Santamarina 1982b: 175 tamén considera o galego occidental máis innovador có oriental: "De maneira provisional poderiamos quizais dicir que a contemplación do mapa dialectolóxico de Galicia dá a impresión de que hai unha zona caracterizada como irradiadora de innovacións (a occidental) e que as ondas innovadoras van alcanzando cada vez menos territorio cara ó oriente canto máis recentes son as innovación"; creo que esta afirmación aínda precisa de demostración. 


\begin{tabular}{|c|c|c|c|c|c|c|c|c|c|}
\cline { 2 - 9 } \multicolumn{1}{c|}{} & 1 & 2 & 3 & 4 & 5 & 6 & 7 & 8 & 9 \\
\cline { 2 - 9 } \multicolumn{1}{c|}{} & IRMÁN & IRMÁ & CAN.PL & ANIMAL.PL & PAXARIÑo & $/ \mathrm{s} /$ & seseo prenuclear & seseo posnuclear & gheada \\
\hline A & irmán & irmán & cans & animás & paxariño & {$[\mathrm{s}]$} & {$[\mathrm{mosa}]$} & {$[\mathrm{lus}]$} & $/ \mathrm{h} /$ \\
\hline B & irmá & irmá & cas & animás & paxariño & {$[\mathrm{s}]$} & {$[\mathrm{mo \theta}]$} & {$[\mathrm{lus}]$} & $/ \mathrm{h} /$ \\
\hline C & irmao & irmá & cas & animás & paxariño & {$[\mathrm{S}]$} & {$[\mathrm{mo} \theta \mathrm{a}]$} & {$[\mathrm{lu} \theta]$} & $/ \mathrm{g} /$ \\
\hline D & irmao & irmá & cais & animais & paxarín & {$[\mathrm{S}]$} & {$[\mathrm{mo \theta}]$} & {$[\mathrm{lu} \theta]$} & $/ \mathrm{g} / /$ \\
\hline
\end{tabular}

Táboa 1. Modalidades do galego segundo Ricardo Carvalho Calero

Santamarina (1982b: 187) cartografa estas modalidades nun mapa con datos obtidos das enquisas do $A L G a$, que presento como Figura $2^{13}$.

Don Ricardo é ben consciente de que existen falas que non comparten tódolos trazos; estas falas, comas as outras, defínense polos trazos que presentan: por exemplo, segundo Carballo Calero (1969: 11), Melide descríbese como 1CD (irmao), 2BCD (irmá) 3BC (cas), 4ABC (animás), 5ABC (paxariño), 6BCD ([s]), 7BCD ([mo日a]), 8AB ([lus]), 9AB (/h/). Deste modo, Melide presenta 4 trazos de A, 8 trazos de B, 7 de C e 4 de D. Segundo don Ricardo, "a maioría das falas locáis redúcense a un dos catro tipos establecidos. Hai outras que presentan caracteres mixtos" (1978: 351). Neste caso, Melide é fundamentalmente unha fala de B (cos trazos 2, 3, 4, 5, 6, 7, 8, 9) cun trazo de $\mathrm{C}(1)$.
Do mesmo xeito, "o galego normativo (académico)” (Carballo Calero 1979: 351) presenta, cambiando lixeiramente a notación, 1A (imán), 2B (irmá), 3A (cans), 4D (animais), 5A (paxariño), 6B ([s]), 7B ([mo日a]), $8 \mathrm{C}([\mathrm{lu} \theta])$ e $9 \mathrm{C}(/ \mathrm{g} /)$, o que dá idea da diversa procedencia dialectal das súas fontes.

Tamén a selección de trazos recibiu algunha crítica. Así, por exemplo, Santamarina (1982b: 167) indica que os trazos 6 (tipo de /s/) e 7 (seseo) van unidos... Hoxe sabemos que hai falas con seseo apical e falas con seseo laminal: isto é, falas do tipo A cun trazo propio das falas tipos B, C e D, que serían zonas de transición entre a modalidade A prototípica e o resto (o propio Santamarina recoñece que hai falas con seseo apical, esquecendo que o método de don Ricardo permite dar conta deste feito como un fenómeno de transición entre modalidades).

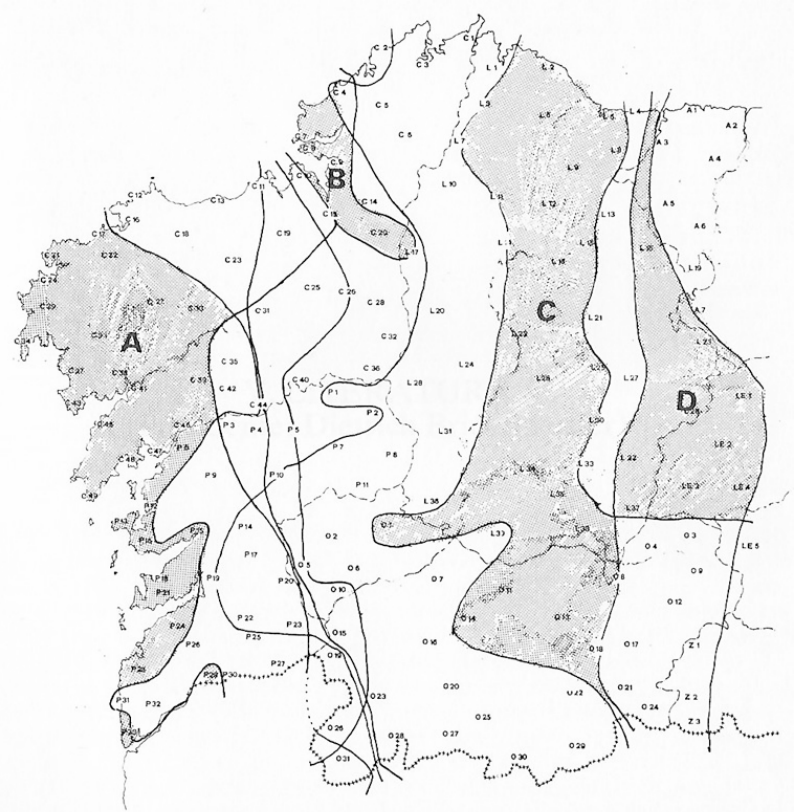

Figura 2. Cartografado das modalidades de Carballo Calero (1969, 1978, 1979) feitas con datos do ALGa por Santamarina (1982b: 187)

13 Nótese que a modalidade A cartografada por Santamarina tería que ser de menor tamaño, pois o lado seu nororiental ten seseo apical e non laminal. 
Tamén critica Santamarina (1982b) que seleccione o trazo irmá para establecer $\mathrm{B}$, pois segundo el "que un dialecto se defina por un rasgo é xustificable se implica alteracións graves no sistema fonético ou morfolóxico ou ben, se, aínda sen afectar ó sistema, encerra unha alteración moi notable na sustancia da expresión". En primeiro lugar, B non se define só pola variante irmá de 1, senón por máis trazos. Con todo, don Ricardo selecciona como variable 1 para crear as súas modalidades os resultados de -ANUM: -án, -ao e -á...; son, polo tanto, as variantes internas desta variable 1 o que ordena, de modo que en B aparece a variante irmá, coma en A aparece irmán e en $\mathrm{C}$ e D irmao; en definitiva, o poder distinguidor de irmá para o masculino é o mesmo có de irmán ou o de irmao. Por outra parte, ninguén a día de hoxe será capaz de negar importancia destas isoglosas: aparecen en calquera descrición dialectal do galego desde que Fernández Rei (1982: 282; 1985b: 92) as usara para separar galego occidental de central.

Sánchez Rei (2011: 355) tamén encontra problemas no tratamento do seseo: as falas con seseo prenuclear tamén presentan seseo posnuclear, pero non á inversa... Non acabo de ver que problema se oculta neste feito; existen tres tipos de modalidades: con seseo total, só con seseo posnuclear, sen ningún tipo de seseo. Deste xeito, un dos trazos que define A fronte a tódalas outras modalidades é seseo prenuclear, de modo que só forman parte do prototipo $\mathrm{A}$ as falas que presenten tódolos trazos que definen esta modalidade; do mesmo xeito, A oponse a B por este e outros trazos, do mesmo xeito que B se opón a $\mathrm{C}$ e a $\mathrm{D}$ por outros.

Fernández Rei (1994: 99) tamén critica que don Ricardo non teña en conta que no galego de Asturias, galego oriental, se diga animales e non animais. Porén, na visión de don Ricardo, o galego de Asturias mostraría trazos orientais (coma as formas camín) e trazos de transición ó ástur-leonés (coma animales); polo tanto, as falas galegas de Asturias non serían representantes prototípicas do galego $\mathrm{D}$, algo que a teoría prevía, senón formas de transición ó ástur-leonés (algo que moitos aseguran, por exemplo, Fernández Rei 1990: 18-19, e que Don Ricardo anunciara).

Como mostran Coseriu e Porzig, a existencia dunha modalidade pura, central, prototípica, xustifícase por conter os nove trazos que se lle atribúen. A, B, C e D defínese por conter tódolos trazos pertinentes. O resto, son transicións.

\section{Conclusións}

Neste traballo pretendín analizar o labor de Ricardo Carvalho Calero como dialectólogo: en concreto, tratei a súa proposta de clasificación dialectal. Como acabo de mostrar e vén sendo tradicional na nosa dialectoloxía, don Ricardo insistiu na unidade básica do galego popular e negou a existencia de dialectos, se por estes entendemos entidades emic, agrupacións de falas cunha personalidade lingüística tal que os seus falantes poidan identificalas, segregalas e nomealas fronte a outras agrupacións; ou cunha diversidade interna tal que impida ou dificulte a comunicación entre os falantes das diversas variedades da lingua.

Consciente da variación que efectivamente existe, prefire buscar un termo máis neutro ou libre de connotacións á hora de crear agrupacións xeolingüísticas: escolle a denominación modalidades; estas agrupacións establéceas o lingüista a partir do estudo da distribución xeográfica das variantes xeolingüísticas que realizan nove variables preseleccionadas; por esta razón, as modalidades son entidades etic.

No seu caso, as variables empregadas son: 1, resultados da terminación latina -ANUM (coas variantes; irmán, irmá, irmao); 2, resultados de -ANAM (irmán, irmá); 3, resultados de -ANES/-ONES (cans, cas, cais); 4, resultados de -ALES (variantes: animás, animais); 5, resultados de -INUM (variantes: paxariño, paxarín); 6 , realizacións de /s/ (variantes: apical, laminal); 7, resultados de /ts/ e /dz/ prenucleares medievais (variantes: seseo prenuclear, cetaísmo prenuclear: mosa ou moza); 8, resultados de /ts/ posnuclear medieval (variantes: seseo posnuclear ou cetaísmo posnuclear: lus ou luz); e 9, resultado de /g/ (variantes: gheada, preservación de /g/). Don Ricardo non xustifica claramente por que selecciona estes trazos (e non outros), que parecen ser escollidos por produciren consciencia dialectal, nin indica de onde toma os datos, nin se refire nunca ós datos contidos no ALPI 1962.

Do cruzamento destas variantes xeolingüísticas obterá catro modalidades prototípicas, A, B, C, D, que se definen cada unha delas por posuír tódalas variantes seleccionadas; entre estas modalidades prototípicas existen outras variedades de transición que se caracterizan por compartir máis ou menos trazos coas modalidades prototípicas. Unhas modalidades parecen máis conservadoras que outras e mesmo unhas parecen ser evolucións das outras. Don 
Ricardo chega, incluso, a propor a comparación cuantitativa do galego común que describe na súa Gramática coas modalidades (cf. Sousa 2020).

Pola miña parte, debo acabar indicando que, persoalmente, non creo na existencia real de modalidades, bloques ou áreas: só creo na existencia do contínuum xeolecta $1^{14}$. Aquelas entidades son ficcións útiles e convenientes para ordenar o espazo xeolectal, pero ningunha das fronteiras entre linguas, modalidades, bloques ou áreas impide o movemento individual e real dos trazos. Estes xeralmente cabalgan libres ó longo de linguas, dialectos, modalidades, bloques ou áreas, con independencia das fronteiras que os lingüistas tracen.

En fin, neste traballo mostro que a proposta de don Ricardo se sostiña nun método de traballo cun fundamento sólido nunha parte da teoría dialectolóxica europea da época e comento algunhas das críticas que se lle fixeron. En definitiva, a pesar da pouca información con que don Ricardo contaba (e á marxe de posibles discrepancias teóricas nas que resulta imposible entrar neste traballo), penso que a súa organización das falas galegas estaba en xeral teoricamente ben fundamentada e segue a merecer o noso respecto.

\section{Referencias bibliográficas}

Alonso Montero, Xesús (1969): O que compre saber da lingua galega. Buenos Aires: Editorial Alborada. Alonso Pintos, Serafín (2000): "O ideal de lingua na Gramática de Carballo Calero", Grial 147, pp. 461-474.

ALPI 1962 = Atlas Lingüístico de la Península Ibérica I. Fonética, I. Madrid: Consejo Superior de Investigaciones Científicas.

Álvarez, Rosario (2003): “A gramática galega”, en Henrique Monteagudo e Xan M. Bouzada (eds.): O proceso de normalización do idioma galego 1980-2000. Volume III. Elaboración e difusión da lingua. Santiago de Compostela: Consello da Cultura Galega, pp. 131-163, DOI: https://doi.org/10.1558/sols.v6i2.305.

(2011): "A gramática galega no século XX. O contributo de Carvalho Calero", en Carlos Caetano Biscainho Fernandes e Xosé Manuel Sánchez Rei (eds.): Ricardo Carvalho Calero: ciencia, literatura e nación. A Coruña: Universidade da Coruña, pp. 13-29, DOI: https://doi.org/10.17979/ spudc.9788497497718.013.

Badía Margarit, Antonio (1951): Gramática histórica catalana. Barcelona: Noguer.

Carballo Calero, Ricardo (1966): Gramática elemental del gallego común, primera edición. Vigo: Galaxia. (1968): “O galego na Universidade", en O porvir da lingua galega. Lugo: Círculo de las Artes / Instituto de Estudios, pp. 39-46.

(1969): "Sobre os dialectos do galego", Grial 23, pp. 1-15.

(1978): "Sobre dialectoloxía do galego", Grial 61, pp. 348-353.

(1979): Gramática elemental del gallego común, séptima edición. Vigo: Galaxia.

Cintra, Luis F. Lindley (1971): "Nova proposta de classificação dos dialectos galego-portugueses”, Boletim de Filologia 22, pp. 81-116.

Coseriu, Eugenio (1981): "Los conceptos de «dialecto», «nivel» y «estilo de lengua» y el sentido propio de la dialectología”, Lingüistica Española Actual 3, pp. 1-32.

- (1985 [1956]): “La geografía lingüística”, en El hombre y su lenguaje. Madrid: Gredos: pp. 103-158.

Dubert-García, Francisco (1995): “Algúns fenómenos morfolóxicos do galego de Santiago", Cadernos de lingua 11, pp. 71-101.

_ (2000): "Sons e letras nas gramáticas clásicas do galego", en José Luís Rodríguez (ed.): Estudos dedicados a Ricardo Carvalho Calero. Santiago de Compostela: Universidade de Santiago de Compostela / Parlamento de Galicia, t. 1, pp. 463-476.

- (2020a): "O galego, unha lingua sen dialectos: olladas sociais e lingüísticas sobre a variación dialectal”, Estudios románicos 29, pp. 147-163, DOI: https://doi.org/10.6018/ER.402591.

- (2020b): "Algunhas notas sobre a Gramática elemental del gallego común", en Francisco Cidrás (ed.): Ricardo Carvalho Calero. As formas do compromiso. Santiago de Compostela: Universidade de Santiago de Compostela, pp. 255-281.

14 Xa Santamarina 1982b: 175 mostrara certo escepticismo ante a fragmentación do galego agrupamentos menores, pois, tras describir a situación de contínuum xeolectal, conclúe que "persisten as divisións de oriental e occidental (continental e atlántico) pero prescíndese da arbitrariedade de considerar que a fronteira está neste ou naquel fenómeno". 
(2021): “Lo que el ALPI le ofrecía a la lingüística gallega en 1962”, Dialectologia 9 (Special issue), pp. 39-67, DOI: https://dx.doi.org/10.1344/dialectologia2021.2021.3.

Fernández Rei, Francisco (1982): "Bloques e áreas lingüísticas do galego moderno”, Grial 77, pp. 257-296. (1985a): “Áreas lingüísticas do galego actual”, en Aina Moll (ed.): Actes. XVIe Congrès Internacional de Lingüistica i Filologia Romàniques (Palma de Mallorca, 1980). Palma de Mallorca: Moll, vol. 2, pp. 485-498.

(1985b): "Variedades dialectales del gallego", Revista de Filología Románica 3, pp. 85-99.

(1990): Dialectoloxía da lingua galega. Vigo: Xerais.

(1994): “Áreas lingüísticas do galego”, en Günter Holtus, Michael Metzeltin e Christian Schmit (eds.): Lexikon der Romanistischen Linguistik. Tübingen: Niemeyer, VI/2, pp. 98-110.

Freixeiro Mato, Xosé Ramón (2018): "Novas achegas ao debate gramatical na Academia Galega na década de 60 da anterior centuria", Estudos de Lingüistica Galega 10, pp. 55-72.

García de Diego, Vicente (1909): Elementos de gramática histórica gallega (fonética-morfología). Burgos: Hijos de Santiago Rodríguez.

González González, Manuel (2020): “A Gramática elemental del gallego común e a creación da cátedra de galego na USC, dúas referencias na historia do galego do séc. XX”, en Anxo Tarrío e Armando Requeixo (eds.): Estudos arredor de Ricardo Carvalho Calero. Cadernos Ramón Piñeiro XL. Santiago de Compostela: Centro Ramón Piñeiro, pp. 117-136.

Henríquez Salido, Maria do Carmo (1999): “As 'rectificaçons' nas ediçons da Gramática do Professor Ricardo Carvalho Calero”, en Maria do Carmo Henríquez Salido e Miguel Ángel Esparza Torres (eds.): Estudios de historiografía lingüística hispánica ofrecidos a Hans-Josef Niederehe. Vigo: Universidade de Vigo, pp. 73-96.

Labov, William (1983 [1972]): Sociolinguistic patterns, Philadelphia: University of Pennsylvania Press [citado pola tradución española: Modelos sociolingüísticos, Madrid: Cátedra, 1983].

Llera Ramo, Francisco José e Pablo San Martín Antuña (2003): II estudio sociolingüistico de Asturias. Uviéu: Academia de la Llingua Asturiana.

Mariño Paz, Ramón (2002): “A obra lingüística de Carvalho Calero”, en Teresa López e Francisco Salinas (eds.): Actas do Simposio Ricardo Carvalho Calero, Mermoria do século. A Coruña: Universidade da Coruña, pp. 67-106.

Porzig, Walter (1969 [1950]): Das Wunder der Sprache. Probleme, Methoden und Ergebnisse der modernen Sprachwissenschaft. Berna: A. Francke AG. Verlag [citado pola tradución española: El mundo maravilloso del lenguaje. Madrid: Gredos, 1969].

Regueira, Xosé Luís (1996): "Os estudos de lingüística galega”, en Ramón Lorenzo e Rosario Álvarez (coords.): Homenaxe á profesora Pilar Vázquez Cuesta. Santiago de Compostela: Universidade de Santiago de Compostela, pp. 47-67.

Sánchez Rei, Xosé Manuel (2005): "Trazos xerais da tradición gramatical galega", Revista Galega de Filoloxía 6, pp. 93-121, DOI: https://doi.org/10.17979/rgf.2005.6.0.5317.

(2008): "Algunhas observacións sobre a Gramática elemental del gallego común de Ricardo Carvalho Calero", Madrygal. Revista de Estudios Gallegos 11, pp. 101-112, https://revistas.ucm.es/index. $\mathrm{php} / \mathrm{MADR} /$ article/view/MADR0808110101A.

(2011): Lingua galega e variación dialectal. Ames: Laiovento.

Santamarina, Antón (1982a): "Gramática", en Gran Enciclopedia Gallega. Santiago de Compostela / Gijón: Silverio Cañada, t. XVI, pp. 191-195.

(1982b): "Dialectoloxía galega: historia e resultados", en Dieter Kremer e Ramón Lorenzo (eds.): Tradición, actualidade e futuro do galego: Actas do Coloquio de Tréveris. Santiago de Compostela: Xunta de Galicia, pp. 153-187.

Sousa, Xulio (2020): "From regional dialects to the standard: Measuring linguistic distance", Languages 5/1, 4 (Special Issue. Contemporary Perspectives in Geolinguistics and Dialectology), DOI: https:// www.mdpi.com/2226-471X/5/1/4.

Zamora Vicente, Alonso (1986 [1953]): "De geografía dialectal: -ao, -án en gallego", Nueva Revista de Filología Hispánica 7, pp. 73-80 [citado pola edición de Estudios de dialectología hispánica. Santiago de Compostela: Universidade de Santiago de Compostela, 1986, pp. 27-34, https://doi.org/10.24201/ nrfh.v7i1/2.297. 